\title{
Total Liability for Excessive Harm
}

\author{
Robert Cooter and Ariel Porat
}

\begin{abstract}
The total social harm caused by everyone is often verifiable, and the harm that each actor causes is often unverifiable. In these circumstances, the authorities lack the information necessary to implement the usual liability rules or externality taxes. We propose a novel solution: hold each participant in the activity responsible for all of the excessive harm that everyone causes. By excessive harm we mean the difference between the total harm caused by all injurers and the optimal total harm. We show that the rule of total liability for excessive harm creates incentives for efficient precaution and activity level. Consequently, actual harm is not excessive and actual liability is nil. The authorities gain control over social harm without having to monitor individuals, and individuals do not have to pay damages or conform to bureaucratic regulations. This rule has many practical advantages, especially in cases involving harm to the environment.
\end{abstract}

\section{INTRODUCTION}

The social harm caused by each individual is often unverifiable, by which we mean not provable to a third party. For example, an environmental

ROBert COOTER is Herman Selvin Professor of Law, University of California, Berkeley. ARIEL PORAT is Alain Poher Professor of Law, Tel Aviv University Faculty of Law, and Visiting Professor, University of Chicago School of Law. For research assistance, the authors are grateful to Jennifer Shkabatur and Yael Bregman-Eschet. For helpful comments, the authors are grateful to Ronen Avraham, Oren Bar-Gill, David Dana, Aaron Edlin, Melvin Eisenberg, Daniel Farber, David Gilo, Assaf Hamdani, Louis Kaplow, Ofer Kot, Saul Levmore, Barak Medina, Oren Perez, Eric Posner, David Schorr, Marshall Shapo, Catherine Sharkey, Peter Siegelman, Stephen Sugarman, Cass Sunstein, Avraham Tabach, Eric Talley, John Witt, Omri Yadlin, an anonymous referee, participants in the law faculty workshops at the University of Chicago, Columbia University, Haifa University, Northwestern University, and Tel Aviv University, participants in the law and economics workshops at the University of California, Berkeley, and Harvard University, and participants in the annual meeting of the American Law and Economics Association, which was held at New York University (May 2005). 
agency often cannot prove the extent of each polluter's emissions. In these circumstances, implementing the usual liability rules or externality taxes is difficult or impossible. For example, implementing a rule of strict liability requires verifying the damage that individual injurers actually cause. The same is true for an externality tax (Pigouvian tax), a negligence rule, a fine for excessive emissions, or a system of transferable pollution rights.

In many circumstances where the individual's contribution to social harm is unverifiable, the total harm caused by everyone is verifiable. For example, the environmental agency can usually measure total pollution easier than it can measure the harm caused by each individual polluter. We propose a novel rule to control social costs in these circumstances: hold each participant in the activity responsible for all of the excessive harm that everyone causes. By excessive harm we mean the difference between the total harm caused by all injurers and the optimal total harm. We call this rule total liability for excessive harm.

We will show that total liability for excessive harm creates incentives for efficient precaution and activity level. Incentives are efficient because each injurer internalizes the marginal social benefit and cost of reducing the harm that he or she causes. Consequently, actual harm is not excessive, and actual liability is nil. For example, the environmental agency can set a target for clean air and announce that each factory is liable for pollution by all factories that exceed the target. Since the liability rule causes the factories to hit the target, they pay no damages. Thus the environmental agency gains control over emissions without having to monitor individual polluters, and the polluters do not have to pay damages or conform to bureaucratic regulations. The rule of total liability has practical advantages, and we commend its use under three conditions: (1) total harm is verifiable, (2) optimal total harm is calculable, and (3) the number of injurers is not too large.

Our proposal builds on existing literature. Holmstrom's (1982) classical paper, "Moral Hazard in Teams," explains that a principal can provide efficient incentives to two agents with unverifiable outputs by paying bonuses that correlate with total output by both agents. ${ }^{1}$ Some previous papers analyze the incentive effects of different liability rules when consumers harmed by a defective drug cannot prove which of several manufacturers supplied it to them (see Porat and Stein 2001, pp.

1. The idea takes a somewhat different form in contracts in our theory of antiinsurance (Cooter and Porat 2002). 
58-69, 130-59). Kaplow and Shavell (2002, pp. 10-11) suggest that when firms create indistinguishable externalities, the state can tax each firm at the rate of the marginal harm, which depends on the total level of the externality. Edlin and Karaca-Mandic (2006) estimate empirically the externalities from automobile accidents by taking into account that each car in a collision could have avoided it by not driving, so each of them should pay the total cost of the accident. ${ }^{2}$ In the paper closest to ours, Segerson (1988) analyzes the consequences of taxing each polluter for total pollution that exceeds the social optimum while also subsidizing each polluter for total pollution that falls short of the social optimum. ${ }^{3}$

Section 2 describes the basic model of total liability for excessive harm, Section 3 compares it to other liability rules, Section 4 refines and qualifies the model, and Section 5 gives examples of its application. ${ }^{4}$

\section{THE MODEL}

We begin by contrasting strict liability and liability for excessive harm for an individual.

\subsection{Example 1}

An industrialist operates a factory whose smoke causes harm $h$ to the neighbors. Without abatement, harm $h$ equals 150 . Abatement has two forms. First, by taking precautions costing 15 , the factory reduces the actual harm by 30 . Second, by reducing production at a cost of 10 in forgone profits, the factory reduces the actual harm by 20 . Efficiency

2. They conclude that a correcting Pigouvian tax could raise $\$ 45$ billion annually in California alone and over $\$ 140$ billion nationally (Edlin and Karaca-Mandic 2006).

3. Miceli and Segerson (1991) proposed a form of total liability for ambient pollution, according to which underachievement of a group's abatement goal results in a tax and overachievement results in a subsidy. For underachievement, Miceli and Segerson's tax has the same consequences as our rule of total liability for excessive harm. For overachievement, however, Miceli and Segerson's subsidy creates a potentially fatal incentive problem. A group that reduces total pollution below the target receives a subsidy equal to a multiple of the total benefit created by its overachievement. Consequently, by overachieving it realizes a private gain and causes a social loss. Overachieving is privately profitable and socially costly. The rule of total liability for excessive harm avoids this problem by not paying subsidies for overachieving relative to the target.

4. Cooter and Porat (2005) contains a mathematical appendix. 
requires both forms of abatement-more precaution and less activityso the socially optimal harm $b^{*}$ equals $100 .^{5}$

In example 1, a rule of strict liability causes the industrialist to choose between not abating and paying damages of 150 or abating at a cost of 25 and paying damages of 100 . Since the latter is cheaper by 25 , the industrialist will abate at the socially optimal level for both precaution and activity level. Similarly, a rule of liability for excessive harm causes the industrialist to choose between not abating and paying damages of 50 or abating at a cost of 25 and paying damages of 0 . Since the latter is cheaper by 25 , industrialist will abate at the socially optimal level for both precaution and activity level.

In general, injurer $i$ 's liability for actual harm $b^{i}$, or injurer $i$ 's liability for excessive harm $\left(b^{i}-b^{i *}\right)$; gives the injurer socially optimal incentives with respect to precaution and activity level. A rule of strict liability creates efficient incentives by making the injurer internalize the total social benefits and costs of precaution and activity level, which include marginal and inframarginal benefits and costs. In contrast, a rule of liability for excessive harm makes the injurer internalize the marginal social benefits and costs of precaution and activity level when harm is excessive. The difference between them is the allocation of inframarginal $\operatorname{costs} b^{i *}$, which does not influence the rational individual's behavior.

To participate in an activity, an actor often has to make an initial investment. To illustrate, a motorist buys a car before driving, and a manufacturer builds a factory before manufacturing. By participating in the activity, injurer $i$ causes harm $b^{i}$. A rule of strict liability causes each potential participant to internalize the social cost of participating. When the rate of participation is not socially optimal, a rule of liability for excessive harm. makes each potential participant internalize the social cost of participating. When the rate of participation is socially optimal, a rule of liability for excessive harm makes participants pay nothing for participation. So both rules give incentives for optimal participation.

Now we modify example 1, which concerns liability for harm caused by an individual, to fit strict total liability-the principle that each injurer is liable for the harm caused by all injurers (for a discussion of the consequences of such a rule, see Golbe and White 1999).

5. Example 1 implicitly assumes that the neighbors can do nothing to reduce harm and that transaction costs prevent the industrialist and the neighbors from solving the problem by private bargaining. 


\subsection{Example 2}

Each of $m$ factories has the same costs as in example 1. Without abating, the $m$ factories cause total social harm $150 \mathrm{~m}$. With abating, they cause $100 \mathrm{~m}$. Socially optimal abatement and the socially optimal number of factories $m^{*}$ result in total social harm $H^{*}$ equal to $100 \mathrm{~m}^{*}$.

In example 2, a rule of strict total liability causes each industrialist to choose between not abating or abating at a cost of 25 and reducing damages by 50 for everyone. Since the latter is cheaper, each industrialist will abate. The rule of strict total liability, however, has two decisive disadvantages. First, since each participant is liable for all of the harm that everyone causes, any injurer who reduces harm by $\$ 1$ saves all injurers $\$ m$. This fact gives injurers an incentive to collude and reduce social harm below the social optimum $H^{*}$. In general, a rule of strict total liability causes collusion, which results in too much precaution and too little activity.

Second, by participating in the activity, injurer $i$ causes harm $h^{i}$ and $i$ is held liable for harm $H$. Since participants are liable for more harm than the harm that they cause, too few will participate. In general, a rule of strict total liability causes too little participation in the activity that triggers liability. ${ }^{6}$ For this reason, discussions of the rule of total strict liability should distinguish between participation, which is suboptimal, and activity level, which is optimal for the actual level of participation.

Now we apply the rule of total liability for excessive harm to example 2 and show that the social optimum is an equilibrium. Assume that each of $m^{*}$ factories is abating optimally. Any factory that decreases expenditures on abatement from 25 to 0 will increase each factory's liability from 0 to 50 and all factories' liability from 0 to $50 \mathrm{~m}^{*}$. Socially optimal abatement is an equilibrium because each injurer internalizes the marginal social cost of decreasing his or her precaution or increasing his or her activity level. In general, when total harm $H$ is a convex function of individual abatement effort, socially optimal abatement $b^{i *}$ by all $m^{*}$ individuals is an equilibrium.

The rule of total liability for excessive harm does not suffer from the two decisive disadvantages of the rule of total strict liability. First, if anyone abates suboptimally, the others gain by helping him or her to correct his or her mistake. Furthermore, when everyone abates optimally,

6. Inducing optimal participation under a rule of strict total liability requires a participation subsidy equal to $H^{*}-b^{* i}$, which can be a very large number. 
liability is zero, so the group cannot gain by abating further. Collusion helps the parties to find the social optimum and remain there.

Second, beginning at the social optimum $m^{*}$, an additional participant would cause social harm $h^{m^{*}+1}$. Relative to the social optimum, this harm is excessive, so everyone's liability would increase by this amount. If the social optimum were a competitive equilibrium with zero profits, then the additional participant would suffer a loss of $h^{m^{*}+1}$. At the social optimum $m^{*}$, it does not pay for anyone else to participate, so $m^{*}$ is an equilibrium. ${ }^{7}$

\section{COMPARING LIABILITY RULES}

Table 1 compares the verifiability requirements and efficiency of different liability rules. The first row of Table 1 indicates the familiar result that when the harm caused by individuals is verifiable, a rule of individual strict liability gives the injurer efficient incentives for precaution, activity level, and participation. The second row indicates that when the harm caused by an individual is verifiable and comparable to the socially optimal harm, a rule of individual liability for excessive harm also gives the injurer efficient incentives for precaution, activity level, and participation. The third row indicates that when individual precaution can be verified and compared to the optimum, a negligence rule gives the injurer incentives for efficient precaution, excessive activity level, and excessive participation.

The fourth row indicates that when actual total harm is verifiable, a rule of total strict liability can be implemented. Under this rule, each injurer internalizes the marginal social cost of changing his or her precaution or activity level, so the rule provides efficient incentives for precaution and activity level. The rule of strict total liability, however, overburdens participating in the activity. Furthermore, by colluding, participants can reduce social harm below the social optimum $H^{*}$ and save themselves liability costs.

The fifth row indicates that when actual total harm and ideal total harm are verifiable, a rule of total liability for excessive harm provides incentives for optimal precaution, activity level, and participation. In

7. Fixed initial costs of an activity constitute nonconvexities. Relatively small nonconvexities do not threaten the usual efficiency analysis in microeconomics (Arrow and Hahn 1971, pp. 169-82). 


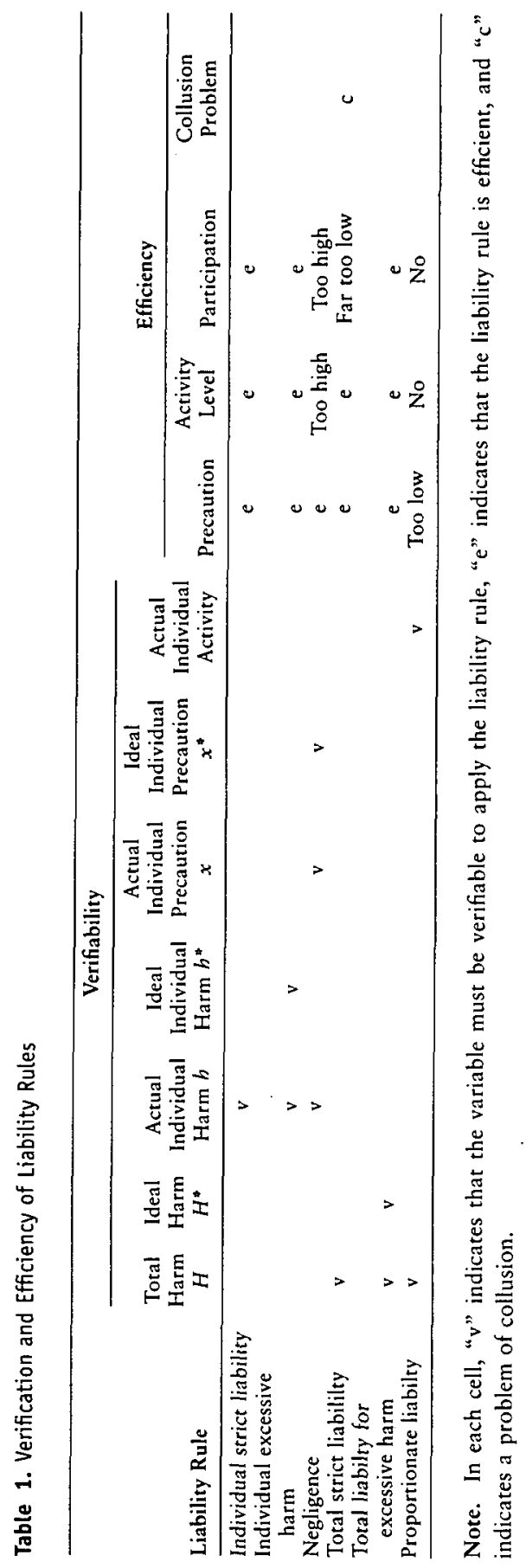


the usual case, collusion is benign because it helps the actors to reach the social optimum $H^{*}$.

Proportionate liability is another rule that can be used when individual harm is unverifiable. Applying a rule of proportionate liability requires verifying the actual total harm and then allocating it to individuals by using a verifiable measure of proportionality. The measure of proportionality indicated in the sixth row is the activity of each individual divided by the total activity of all individuals. The measure of activity might be market share in the sale of a good, miles driven, or fuel consumed. As indicated in Table 1, liability in proportion to activity level creates incentives for too little precaution, and the incentives for activity level and participation are not generally optimal. ${ }^{8}$

\section{REFINING THE MODEL}

Having summarized the results of the basic model in Table 1 , we now turn to some refinements of our analysis of the rule of total liability for excessive harm. We will discuss informally a variety of problems and possibilities.

\subsection{Errors and Irrationality}

When applying the rule of total liability for excessive harm, the authorities may overestimate or underestimate the actual harm $H$ or the ideal social harm $H^{*}$. Overestimating actual harm $H$ and attributing more harm to injurers than they actually cause is mathematically equivalent to underestimating the socially optimal harm $H^{*}$. In either case, instead of observing excessive harm $H-H^{*}$, the authorities observe $H-H^{*}+\varepsilon$, where $\varepsilon$ is an error term.

Consider the consequences when liability is too low because $H-$ $H^{*}+\varepsilon<H-H^{*}$. By satisfying the observed legal standard $H-H^{*}+$ $\varepsilon$, each injurer's liability is nil, so he or she responds with too little precaution and too much activity relative to the social optimum. Now consider the consequences when liability is too high because $\mathrm{H}-$ $H^{*}+\varepsilon>H-H^{*}$. To escape liability, the injurers must reduce harm below the social optimum. At the social optimum, however, the cost to

8. Unless liability under the proportionate rule is imposed in proportion to the exact risks created. In that case, liability equals the harm actually caused by the individual, the rule of individual liability can be applied, and there is no need for a rule of proportionate liability. 
each injurer of reducing social harm exceeds the resulting reduction in an actor's liability. Injurers, consequently, respond with the socially optimal precaution and activity. (As in the case of total strict liability, this behavior is susceptible to collusion and the participation level is too low.)

We apply these conclusions to the case in which error $\varepsilon$ is a random variable. With random errors, each injurer faces the possibility that liability is too low, in which case it would pay to respond with too little precaution and too much activity. Each injurer also faces the possibility that liability is too high, in which case it would pay to respond with optimal precaution and optimal activity level. If the random error is biased toward liability that is too low $[E(\varepsilon)<0]$ or unbiased $[E(\varepsilon)=0]$, then each injurer will respond with too little precaution and too much activity. If the random error is biased toward liability that is too high $[E(\varepsilon)>0]$, then, as the bias increases, each injurer will respond by increasing precaution and reducing activity level until their values approach the social optimum.

Having discussed errors by authorities, we extend our analysis to errors by injurers. Assume that some injurers fail to act in their rational self-interest. Let $H$ denote the total harm that is individually rational, and let $\varepsilon$ denote the error caused by some actors failing to act in their rational self-interest. The actual harm equals $H+\varepsilon$, and everyone is liable for $H-H^{*}+\varepsilon$. As the notation makes clear, this form of error by some actors is mathematically identical to errors by the authorities in applying the liability rule. We have already explained the incentive effects on rational actors when $\varepsilon$ is negative or positive or a random variable.

The preceding discussion assumes that errors by authorities or injurers add to, or subtract from, the actual harm $H$ or the optimal harm $H^{*}$. Additive error is relatively simple to analyze because it often does not affect marginal values. We will not explicitly analyze any other form of error, but we mention briefly how they can change our conclusions. Our conclusions would be different if the error multiplied the actual harm $H$ or optimal harm $H^{*}$. To illustrate multiplicative error, the authorities may underestimate actual harm by 10 percent, or the authorities may overestimate the socially optimal harm by 15 percent, or an injurer may underestimate his or her individually rational precaution by 20 percent. Multiplicative errors change the preceding conclusions because they affect marginal values.

If there are many injurers, the possibility is high that at least one of 
them will make an error and cause excessive harm. Furthermore, when there are many injurers, excessive harm caused by a few of them imposes liability costs on many others. For these reasons, the rule of total liability for excessive harm ceases to be practical when the number of injurers becomes very large. For example, the rule is impractical for assessing damages against drivers in Los Angeles for excessive pollution.

\subsection{Search}

When actors make errors, they can also learn from their mistakes and correct them. Thus, when the authorities have difficulty estimating the optimal social harm $H^{*}$, they might search for the optimum and converge toward it by iteration. To begin the search, they might set the legal standard, denoted $H_{i}$, above the social optimum $H^{*}$ in the first year and thus allow more harm than the social optimum. When $H_{t}$ is higher than the social optimum $H^{*}$, all the firms will meet the target and pay no damages. In the next year, the authorities might decrease the legal standard $H_{i}$. The authorities can repeat this process over several years. As $H_{t}$ decreases, eventually a point will be reached where further increases in abatement cost a firm more than the reduction in liability, so the firms will fall short of the target and begin to pay damages $H-H_{t}$. When this happens, the authorities know that $H_{t}$ is marginally lower than $H^{*}$, so they should increase $H_{t}$ slightly and stop making changes. In brief, the authorities can proceed iteratively until the firms reveal that their marginal cost of abatement equals the marginal social cost of the social harm. This is essentially the same process proposed in theoretical models of search for the Hand Rule standard of negligence or the optimal Pigouvian tax (Cooter, Kornhauser, and Lane 1979).

After searching and finding the social optimum $H^{*}$, the authorities should be alert to the possible emergence of new technologies that lower abatement costs and cause the optimal harm $H^{*}$ to decrease. In response to technical improvement, the authorities must decrease the target $H_{t}$ in order to keep it equal to the social optimum $H^{*}$. If they do not, actors will have deficient incentives to adopt new technologies.

\subsection{Victims' Incentives}

We have been assuming that injurers can reduce social harm and victims cannot reduce it. Now we assume that victims can reduce social harm, and we discuss the incentives that alternative liability rules give them. Our discussion is very brief because its conclusions are familiar in the existing economic analysis of accidents. In general, when victims do not 
receive compensation, they internalize the benefits as well as the costs of their actions, so victims' incentives are socially efficient. ${ }^{9}$ Consequently, if injurers are liable to the state and not liable to the victims, as with a pollution tax, then victims' incentives are efficient.

Instead of being liable to the state, tort law makes injurers liable to the victims. To simplify the analysis of total liability for excessive harm, assume that there is only one victim who receives all damage payments from $m$ injurers. Under the rule of total liability for excessive harm the victim will try to increase his or her harm beyond the optimal total harm $\left(H^{*}\right)$ as much as he or she can, since for every harm of $\$ 1$ he or she receives compensation of $\$ m$.

This problem arises as long as the authorities set compensation equal to the difference between actual harm and socially optimal harm, $H-$ $H^{*}$. To avoid the problem, the authorities could replace actual harm $H$ in this formula with the hypothetical harm $H^{\sim}$ that would result from the actual behavior of injurers and socially optimal behavior of victims. When liability follows this formula, victims cannot increase the compensation that they receive by deviating from the social optimal precaution and activity level. ${ }^{10}$

\subsection{Bankruptcy}

Externalizing risk through the possibility of bankruptcy is a familiar problem for any liability rule. The problem, however, affects the rule of total liability for excessive harm differently from a rule of individual liability. Under the former rule, each injurer pays for the total excessive harm regardless of the ability of other injurers to pay. If an insolvent actor takes large risks of harming others and the harm materializes, all of the solvent injurers will suffer an increase in their liability costs. Each injurer, consequently, has an incentive to prevent others from behaving irresponsibly. This incentive does not exist under a rule of individual liability for separate harms, where the irresponsible behavior of one injurer does not affect the liability of another injurer. ${ }^{11}$

9. Similarly, a rule of negligence in simple economic models induces nonnegligent behavior by injurers, so victims face the same incentives as under a rule of no liability. This proposition is proved in many places, including Cooter and Ulen (2003, chap. 8).

10. Compare Cooter (1985), which shows that when damages in contract law are liquidated, the promissee will not overrely since reliance will not affect the level of damages.

11. When several injurers create one inseparable harm for which they are all jointly and severally liable, however, the injurers have contribution claims against each other. In these circumstances, the insolvent injurer's proportion of liability will be borne by the 


\subsection{Strategy}

The circumstances for adopting the rule of total liability for excessive harm include the inability of the authorities to verify the harm caused by individuals. Under these circumstances, individuals may be unable to observe the harm that each of them causes. One person cannot react strategically to another's unobservable behavior. Consequently, the assumption of nonstrategic behavior is the natural way to begin to analyze the rule of total liability for excessive harm. For nonstrategic actors, we have shown that the social optimum is an equilibrium under the rule of total liability for excessive harm.

The polar opposite of nonstrategic behavior is perfect collusion. Perfect collusion implies that all actors cooperate with each other to maximize their joint payoffs. In our model, the aim of collusion is to minimize the total cost of liability and abatement for the parties. Under the rule of total liability for excessive harm, the parties minimizes their total cost of liability and abatement by meeting the target $H^{*}$ and avoiding liability. Thus, when the parties collude perfectly, the rule of total liability for excessive harm induces socially optimal results. Indeed, collusion has the advantage of enabling actors to help correct each others' mistakes.

These facts suggest that the rule of total liability for excessive harm will prove robust and practical. There is a danger, however, that collusion over liability and abatement might prompt other harmful forms of collusion, such as collusion over prices. The tools of antitrust law are available to deal with this problem. Another fear is that collusion over liability will lead to political lobbying to set the target level of harm $H_{t}$ above the social optimum. The problem of setting standards and escaping political distortions is not special to our rule of liability.

Another topic to explore is forms of strategic behavior that do not involve cooperation. Assume that each actor can observe the individual harm caused by each of the other actors. A sinister possibility is that an actor threatens to impose liability on himself or herself and everyone else unless they take steps to eliminate liability for everyone. This is a form of the game of "chicken." To play chicken under the rule of total liability for excessive harm, an injurer refuses to abate efficiently in order to force other injurers to abate excessively. Acting on this threat, however, lowers the actor's payoff, so it is not credible. For the threat to be effective, people must believe that the party making it is irrational. Play-

solvent injurers, so each one has an incentive to constrain the others, as under the rule of total liability for excessive harm. 
ing chicken requires overcoming an information obstacle and making others believe that you are irrational. This possibility is too unlikely to present a general objection to the rule of total liability for excessive harm as a practical policy. ${ }^{12}$

Another sinister possibility is that an injurer increases the harm that he or she causes in order to increase the costs of his or her competitors. A firm might engage in the pollution equivalent of predatory pricing. Predatory pricing refers to a situation where a firm temporarily prices below cost in order to drive a competitor out of the market and then raises the price above cost. With a rule of total liability for excessive harm, a firm might temporarily create excessive harm in order to drive a competitor out of the market. After the competitor withdraws from the market, the remaining firm returns to optimal harm and no liability. Or a firm might pursue entry-limiting pollution. Under a rule of total liability for excessive harm, the incumbent firm increases pollution until the liability of a new firm makes entering the market unprofitable.

These problems should not occur often or prove unmanageable. When firms do not compete in the same product markets, they have no reason to practice predatory polluting or limit polluting. ${ }^{13}$ If firms that compete with each other engage in these behaviors, the authorities can extend exiting legal remedies for limit pricing and predatory pricing to these new behaviors.

\section{EXAMPLES}

To show that the rule of total liability for excessive harm is practical, we will describe some real and hypothetical situations in which the rule

12. Notice that without collusion among the other actors, the first actor would never play chicken. To illustrate, suppose that the first actor does not abate and each of the other actors believe that his or her refusal to abate is credible. Nevertheless, after the other actors reduced their excessive harm to zero, none of them will abate, because by definition each of the actors' costs of additional abatement are higher than the harm they could reduce by additional abatement. This proposition is valid with respect to each and every actor, regardless of how the other actors behave.

13. However, even if the firms do not compete in the products market, the firms could still compete over the "right" to pollute. Thus, if the Environmental Protection Agency allows a certain amount of pollution in a specific area, some polluters could find it beneficial to increase pollution in order to drive out of the area other polluters. If the former polluters succeed in their efforts, fewer polluters will later share the "right" to pollute. This concern disappears, however, if the Environmental Protection Agency adapts $H^{*}$ to encompass the number of polluters acting in the area. 
could be applied to great advantage.

\subsection{Industrial Pollution of the Kishon River}

Two petrochemical plants and five fertilizer plants discharge a variety of pollutants, especially metals, into the final $7 \mathrm{~km}$ of the Kishon River where it flows into the Mediterranean Sea at Haifa (Kishon River Authority 2001a). ${ }^{14}$ Measuring the extent of these metals in the river is feasible, but measuring the individual contributions of polluters is not. In 1994, the Kishon River Authority assumed responsibility for full ecological rehabilitation of the river by 2010 (Kishon River Authority 2001b). The Kishon River Authority could pursue its goals by applying the principle of total liability for excessive harm. For each metal, the small number of firms that discharge it would be totally liable for concentrations in the river that exceed the Kishon River Authority's targets.

\subsection{Everglades and Nonpoint Source Pollution}

Phosphorus runs off of farms into the Florida Everglades. Since 1995-96, phosphorus loadings have been compared with a baseline derived from loadings recorded from 1979-88 (see U.S. Environmental Protection Agency 1996). If basin-wide reductions in nutrient load into the Everglades do not meet statutory targets over time, the Agricultural Privilege Tax imposes a property tax increase on all farmers, beginning at $\$ 24.89$ per acre in 1996 and increasing every 4 years to a maximum of $\$ 35$ per acre from 2006 through 2014. However, the farmers in the designated area can escape the tax increase by exceeding an overall 25 percent basinwide phosphorus reduction goal.

Such a tax, whose form corresponds to a rule of total liability for excessive harm, can apply more generally to nonpoint source (NPS) pollution. Section 303(d) of the U.S. Clean Water Act provides the Environmental Proctection Agency with the power to set the total maximum daily load (TMDL) for a type of pollutant and a body of water. Section 319 of the 1987 Clean Water Act requires states to identify water bodies in which control of NPS polluters is necessary and to establish management programs. Sometimes a small number of major sources account for almost all NPS pollution. In these circumstances, each pol-

14. Pollution in the river especially caught the attention of the Israeli public because of the fate of an elite army squad that trained in the polluted water and that now has at least 88 documented cases of malignant tumors in its men. The incidence of cancer in this army unit far exceeds base rates. 
luter could be held liable for total harm caused by pollution that exceeds the TMDL.

\subsection{Fish Cages at Eilat}

As of 2004, 70 percent of the coral reef in the Gulf of Eilat in the Red Sea is dead or seriously damaged, primarily because of fish farms operated by two companies, which the authorities are threatening to close (Israeli Ministry of Environment and the Authority for Nature and Gardens 2004). To avoid closure, the two companies could contract into a rule of total liability for excessive harm, which is practical because the total harm caused by the two companies is verifiable and the individual contributions are unverifiable. Such a contract could halt further damage and remove the public pressure to close the fish farms.

\subsection{Hypothetical Examples}

To conclude, we briefly mention some hypothetical examples that show more possibilities. If soda bottles explode either because Company A supplies defective bottles or Company B overcharges the bottles when filling them, the Consumer Protection Agency could collect a fine from both companies for injuries that exceed the expected rate of injury for companies following the best practices. Similarly, if Hospital A diagnoses melanoma and refers its patient to Hospital B for treatment, the supervising authority could hold each of the hospitals liable for deaths exceeding the expected rate from optimal care by both hospitals. ${ }^{15}$ If a city suffers from pollution by buses operated by three companies, and if city officials can determine with reasonable accuracy the amount of total pollution caused by all buses, the city could fine the three companies for excessive pollution. Finally, if three municipalities around a lake want to prevent overfishing, they could agree to collection of a tax from each of them whenever the stock of fish falls below an accepted target.

\section{CONCLUSION}

In the last century, the rule of strict liability for consumer product injuries displaced the rule of negligence. Problems of proof compelled the change.

15. The two hospitals might respond by refusing to take patients whose survival prospects are below average. For example, Hospital A might not admit patients who delay too long and come to the hospital with an advanced stage of melanoma. This is the same problem of adverse selection that afflicts private medical insurance markets. This problem diminishes or disappears insofar as hospitals must accept all patients in need of care. 
For certain kinds of harm, we believe the same consideration will eventually compel replacing individual liability with the rule of total liability for excessive harm. As we have explained, the rule is practical under three conditions: (1) total harm is verifiable, (2) optimal total harm is calculable, and (3) the number of injurers is not too large. When these conditions are met and the harm caused by individuals is difficult to verify, we recommend adopting the rule of total liability for excessive harm and avoiding the administrative burden of individualized liability, taxes, fines, or transferable rights.

Moralists might reject this recommendation because it imposes collective punishment. On the path to equilibrium, actors could find themselves paying for harms caused by others, and errors or strategic behavior might continue this result in equilibrium. Where actors pay for harms caused by others, however, the excessive harm caused by everyone is usually less than the individual harm caused by each actor. The rule of total liability for excessive harm, consequently, will usually result in lower damages than the rule of strict liability for individual harm. Indeed, the damages will usually be nil. ${ }^{16}$ People are unlikely to complain about collective punishment when each one pays less than under individual liability.

The fact that the rule of total liability for excessive harm creates socially optimal incentives should make it attractive to people who want to promote the public interest. The fact that injurers escape bureaucratic regulation and each injurer's liability equals zero in equilibrium should make the rule more attractive to injurers than most alternatives. In order for people to be attracted to the rule, however, they must understand its consequences. As this paper shows, some consequences are counterintuitive. The difficulty that most people have in understanding the effects of the rule of total liability for excessive harm constitutes the largest obstacle to its acceptance.

16. The argument for the rule's fairness resembles the utilitarian justification of an effective deterrent: an effective deterrent is fair because it does not have to be used. Utilitarian and deontological traditions disagree about whether a very harsh penalty that perfectly deters and never requires use should be praised for its good consequences or condemned for its excessive threat. For a recent contribution to this debate that favors the utilitarian tradition, see Kaplow and Shavell (2001). For environmental law application, see Hsu (2004), which argues for more economics and more efficiency thinking in environmental law. 


\section{REFERENCES}

Arrow, Kenneth J., and Frank H. Hahn. 1971. Markets with Non-convex Preferences and Production. Chapter 7 in General Competitive Analysis. San Francisco: Holden-Day.

Cooter, Robert. 1985. Unity in Tort, Contract, and Property. California Law Review 73:1-51.

Cooter, Robert, Lewis Kornhauser, and David Lane. 1979. Liability Rules, Limited Information, and the Role of Precedent. Bell Journal of Economics 10: 366-73.

Cooter, Robert, and Ariel Porat. 2002. Anti-insurance. Journal of Legal Studies 31:203-32.

- 2005. Total Liability for Excessive Harm. Berkeley Program in Law and Economics Working Paper No. 177. University of California, Berkeley. http: //repositories.cdlib.org/cgi/viewcontent.cgi . article $=11798$ content $=$ blewp.

Cooter, Robert, and Thomas Ulen. 2003. Law and Economics. 4th ed. Reading, Mass.: Addison-Wesley.

Edlin, Aaron S., and Pinar Karaca-Mandic. 2006. The Accident Externality from Driving. Journal of Political Economy 114:931-55.

Golbe, Devra L., and Lawrence J. White. 1999. Market Share Liability and Its Alternatives. Center for Law and Business Paper No. 99-014. New York University. http://ssrn.com/abstract $=209809$.

Holmstrom, Bengt. 1982. Moral Hazard in Teams. Bell Journal of Economics 13:324-40.

Hsu, Shi-Ling. 2004. Fairness versus Efficiency in Environmental Law. Ecology Law Quarterly 31:303-401.

Israeli Ministry of Environment and the Authority for Nature and Gardens. 2004. The Effects of the Fish Farms on the Gulf of Eilat and on the Coral Reef. http://www.sviva.gov.il/Enviroment/Static/Binaries/News/eilat_ madanim_1.pdf (in Hebrew).

Kaplow, Louis, and Steven Shavell. 2001. Fairness versus Welfare. Harvard Law Review 114:961-1389.

- 2002. On the Superiority of Corrective Taxes to Quantity Regulation. American Law and Economics Review 4:1-17.

Kishon River Authority. 2001a. Information on the Kishon River and the Quality of Its Waters. http://www.kishon.org.il/pages/publications/information.php (in Hebrew).

- 2001b. Master Plan for the Kishon River. http://www.kishon.org.il/ pages/publications/tochen.php (in Hebrew).

Miceli, Thomas J., and Kathleen Segerson. 1991. Joint Liability in Torts: Marginal and Infra-marginal Efficiency. International Review of Law and Economics 11:235-49. 
80 / THE JOURNAL OF LEGAL STUDIES / VOLUME 36 (1) / JANUARY 2007

Porat, Ariel, and Alex Stein. 2001. Tort Liability under Uncertainty. Oxford: Oxford University Press.

Segerson, Kathleen. 1988. Uncertainty and Incentives for Nonpoint Pollution Control. Journal of Environmental Economics and Management 15:87-98. U.S. Environmental Protection Agency. 1996. A Tax Incentive for Installing Ag BMPs in the Everglades. Non-point Source News-Notes, October 1996. http: //notes.tetratech-ffx.com/newsnotes.nsf/0/bff4df21f49ed6de8525666a00519 23f?OpenDocument. 